University of Nebraska - Lincoln

DigitalCommons@University of Nebraska - Lincoln

2008

Understanding the Grafting of Telechelic Polymers on a Solid Substrate to Form Loops

Zhenyu Huang

Haining Ji

Jimmy W. Mays

Mark D. Dadmun

Follow this and additional works at: https://digitalcommons.unl.edu/usdoepub

Part of the Bioresource and Agricultural Engineering Commons

Huang, Zhenyu; Ji, Haining; Mays, Jimmy W.; and Dadmun, Mark D., "Understanding the Grafting of Telechelic Polymers on a Solid Substrate to Form Loops" (2008). US Department of Energy Publications. 71.

https://digitalcommons.unl.edu/usdoepub/71

This Article is brought to you for free and open access by the U.S. Department of Energy at DigitalCommons@University of Nebraska - Lincoln. It has been accepted for inclusion in US Department of Energy Publications by an authorized administrator of DigitalCommons@University of Nebraska - Lincoln. 


\title{
Understanding the Grafting of Telechelic Polymers on a Solid Substrate to Form Loops
}

\author{
Zhenyu Huang, ${ }^{\dagger}$ Haining Ji, ${ }^{\dagger}$ Jimmy W. Mays, ${ }^{\dagger,}$ and Mark D. Dadmun $*,+$, \\ Department of Chemistry, University of Tennessee, Knoxville, Tennessee 37996, and Chemical Science \\ Division, Oak Ridge National Laboratory, Oak Ridge, Tennessee 37831
}

Received August 14, 2007; Revised Manuscript Received November 16, 2007

\begin{abstract}
Recent experimental and theoretical studies have demonstrated that relative to singly tethered chains, the presence of polymer loops at interfaces significantly improves interfacial properties such as adhesion, friction, and wettability. In the present study, a simple system was studied to examine the formation of polymeric loops on a solid surface, where the grafting of carboxylic acid terminated telechelic polystyrene from the melt to an epoxy functionalized silicon is chosen. The impact of telechelic molecular weight, grafting temperature, and surface functionality on the telechelic attachment process is studied. It was found that grafting of the telechelic to the surface at both ends to form loops is the primary product of this grafting process. Moreover, examination of the kinetics of the grafting process indicates that it is reaction controlled. Fluorescence tagging of the dangling ends of singly bound chains provides a mechanism to monitor their time evolution during grafting, and these results indicate that the grafting process is accurately described by recent Monte Carlo simulation work. The results also provide a method to control the extent of loop formation at interfaces and therefore provide an opportunity to further understand the role of the loops in the interfacial properties in multicomponent polymer systems.
\end{abstract}

\section{Introduction}

Grafting of polymers onto a substrate provides a robust approach to modify the properties of solid surfaces, including adhesion, ${ }^{1-4}$ friction, ${ }^{5-9}$ and wettability. ${ }^{10-18}$ A widely used pathway to graft polymers is to react end-functionalized polymers to functional groups on a substrate, i.e., the grafting to process. Much experimental, theoretical, and simulation work has been conducted with the goal of understanding the grafting kinetics and structure of the grafted chains.

Most of the work in this arena has focused on studies of singly tethered chains, however, limited attention has been paid to multiply bound chain systems ${ }^{19}$ that can be generated by doubly end-functionalized polymers (telechelic polymers or telechelics), where loops are expected to be formed. These systems are important because the resulting interfacial structures should exhibit enhanced interfacial properties relative to those modified with singly tethered chains. For example, Shull ${ }^{10}$ has noted that, in contrast to tail configurations, loop configurations more autophobically dewet homopolymer. Recent work by Dadmun and co-workers ${ }^{20-24}$ has further demonstrated that the adhesion between polymer phases can be improved by introducing polymer loops at interfaces. Irvine et al. ${ }^{25}$ also showed that star polymers tethered by their ends (thus creating loops) provide more effective resistance to protein adsorption than the tethered linear polymers at the same grafting density. Thus, there is clear evidence that attaching a polymer chain to the surface by multiple points can provide superior surface properties; however, very little is known about the attachment process and structure of such grafted surfaces.

Thus, a series of experiments were completed to monitor the kinetics and mechanism of grafting telechelic polymers to

\footnotetext{
Department of Chemistry, University of Tennessee.

$\doteqdot$ Chemical Science Division, Oak Ridge National Laboratory.
}

functionalized surfaces. In particular, the influence of molecular weight, annealing temperature, annealing time, and surface functionality on the structure and kinetics of the ultimate graft is presented. Whether the grafting process is diffusion or reaction controlled is also carefully examined. The present study provides a simple model system to understand the formation and structure of these novel interfacial modifiers, providing an opportunity to further understand the role of loops on the interfacial properties of multicomponent polymer systems and their formation processes. The polymer/hard substrate system was chosen as a model system in our study due to the complexity of completing and analyzing a similar study on a polymer/polymer interface. For instance, the interfacial width, ${ }^{26-29}$ of a soft polymer/polymer interface can broaden due to the thermodynamic interaction between the two polymers, which may also allow interfacial corrugation or roughening. ${ }^{30-33}$ In the current work, by fixing the surface functionality and the interfacial width, the system is simplified, allowing us to readily elucidate the role of molecular weight, temperature, and surface functionality in the grafting process.

\section{Experimental Section}

Materials. A series of telechelic polystyrene, deuterated or hydrogenated, with carboxylic acid group at both chain ends, were anionically synthesized. The details of sample preparation and characterization can be found elsewhere. ${ }^{34}$ The molecular characteristics of these polymers are listed in Table 1 , where the D and $\mathrm{H}$ in the name of the sample refers to deuterated and protonated polystyrene, respectively. The polymer samples were dissolved in HPLC grade toluene (Fisher Scientific), which was filtered using a $0.02 \mu \mathrm{m}$ filter before use. Sulfuric acid $(95 \%)$ and $30 \% \mathrm{w} / \mathrm{w}$ hydrogen peroxide, and absolute ethanol used in this study were all certified ACS grade (Fisher Scientific) and used as received. The nanopure water used in this study was purified using a MilliPore water treatment apparatus. The epoxysilanes (3-Glycidyloxypropyl)trimethoxysilane (GPS) and 3-methoxypropyltrimethox- 
ysilane (MPS) were obtained from Gelest, Inc., and stored in a nitrogen-filled glovebox. The structure of these two silanes is shown below:<smiles>CO[Si](CCCOCC1CO1)(OC)OC</smiles>

(3-Glycidyloxypropyl)trimethoxysilane<smiles>COCCC[Si](OC)(OC)OC</smiles>

3-methoxypropyltrimethoxysilane

The fluorescence probe, 1-Pyrenyldiazomethane (PDAM), was purchased from Molecular Probes, Inc. (Eugene, OR). PDAM was dissolved in ethyl acetate and stored at $-20{ }^{\circ} \mathrm{C}$. To keep it fresh, the solution was made every 2 weeks.

The one-side polished single-crystal silicon wafers with $\{110\}$ orientation were purchased from Wafer World, Inc (West Palm Beach, FL). Before treatment, they were cut into pieces of ca. $1 \times$ $2 \mathrm{~cm}^{2}$.

Sample Preparation. The preparation of an epoxysilane monolayer on a silicon wafer is based on the procedure introduced by Luzinov et al. ${ }^{35-38}$ The silicon wafers were first precleaned in a bath of fuming $\mathrm{H}_{2} \mathrm{SO}_{4} / 30 \% \mathrm{H}_{2} \mathrm{O}_{2}$ (3:1) piranha solution followed by rinsing with nanopure water and drying with a dry nitrogen stream. After cleaning, the silicon wafers were immediately moved into a nitrogen-filled glovebox and immersed in $1 \%$ solution of epoxysilane in toluene. After $24 \mathrm{~h}$, the wafers were removed from solution and rinsed alternatively with ethanol and toluene three times, sonicated in ethanol for $30 \mathrm{~min}$, rinsed again with ethanol, and finally dried under a stream of dry nitrogen. The formed epoxysilane layer was then characterized using ellipsometry and contact angle measurement.

The telechelic polymers used in this project were synthesized by anionic polymerization techniques as previously described. ${ }^{34}$ The characteristics of these polymers are provided in Table 1 . To create the graft structure, these telechelics were spin-coated from toluene solutions onto a functionalized wafer with a spin rate $2500 \mathrm{rpm}$. The thickness of the polymer thin film was controlled by the concentration of the solution, but also varies slightly with the molecular weight of polymers. The coated wafers were annealed in a vacuum oven at high-temperature $\left(>T_{\mathrm{g}}\right)$, which results in the grafting of the polymers onto the substrate due to the reaction between the carboxylic groups and epoxy groups. The unreacted polymers were then removed by multiple washing with toluene and sonication in toluene for $20 \mathrm{~h}$. The thickness of the grafted layer was measured by ellipsometry. No further decrease in thickness was observed with further sonication beyond $20 \mathrm{~h}$.

Sample Characterization. Measurements of the dry layer thickness for the epoxysilane monolayer and polymer thin film were made on an EL X-02C ellipsometer with an angle of incident $70^{\circ}$. Prior to the preparation of the silane layer and polymer film, the thickness of the silicon oxide layer was measured and found to be in the range of 1.5 to $2 \mathrm{~nm}$. The refractive indexes of $\mathrm{SiO}_{2}$, epoxysilane, and PS were assumed to be equal to the bulk values 1.46, 1.429, and 1.59, respectively. At least five measurements from different locations on the wafers were averaged to give the reported thickness values. It should be noted that for ultrathin films $(<2$ $\mathrm{nm})$, the refractive index is thickness dependent and often overestimated, which can lead to an underestimate in the film thickness. ${ }^{39-41}$ The measured thicknesses of polymer thin films were also used to estimate the surface density of chains $(\sigma)$, which is defined as the number of chains per unit area. Contact angle measurements were performed on a model 100-00 contact angle goniometer (RaméHart, Inc.)
Table 1. Molecular Characteristics of Telechelic Polystyrene Used in the Present Study

\begin{tabular}{lrl}
\hline sample & $M_{\mathrm{w}}(\mathrm{g} / \mathrm{mol})$ & PDI \\
\hline H3.5K & 3500 & 1.14 \\
D3.7K & 3700 & 1.08 \\
D14K & 14000 & 1.09 \\
D32K & 32000 & 1.14 \\
D55K & 55000 & 1.08 \\
D125K & 125000 & 1.05
\end{tabular}

To monitor the amount of singly grafted chains during the grafting process, the fluorescent probe 1-Pyrenyldiazomethane (PDAM) was employed to label the free carboxylic acid groups on singly bound chains. PDAM is able to react with the carboxylic acid group at room temperature without catalyst and produces intensely fluorescent esters. ${ }^{42}$ Both PDAM and products are stable. In addition, it has been shown that PDAM is highly specific for carboxylic acid groups. ${ }^{43}$ Due to these advantages, PDAM has been used as a fluorescence labeling reagent for chromatographic analysis $^{42,44}$ and also in the solid-phase reaction system. ${ }^{43}$ The reaction between PDAM and carboxylic acid is displayed below:

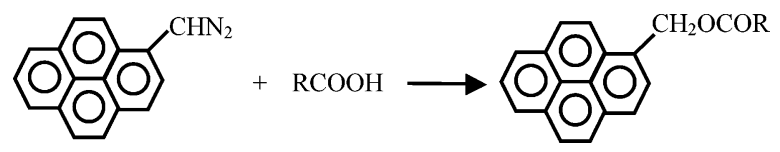

During the labeling process, the substrate coated with the telechelic polymers was immersed in a $0.01 \%(\mathrm{w} / \mathrm{v})$ ethyl acetate solution of PDAM. Kinetics studies showed that the reactions were complete after $6 \mathrm{~h}$. The substrate was then removed from the PDAM solution, washed several times, and sonicated in ethyl acetate to remove unreacted PDAM. After the sample was dried with a dry nitrogen stream, the fluorescence spectra were recorded immediately. Blank tests were also performed to calibrate physically adsorbed PDAM on the epoxysilane monolayer and polystyrene. To check the interaction between the bound polystyrene and PDAM, a monofunctionalized polystyrene was used to generate a grafted layer with singly bound chains. It was found that the fluorescence intensity measured for wafers coated with epoxysilane monolayer or polystyrene without a dangling functional group are negligible relative to the fluorescence obtained for grafted telechelic polymers in the present study.

All fluorescence spectra were collected on an Aminco-Bowman series 2 luminescence spectrometer. A continuous high power xenon lamp was utilized as the light source. The spectra were recorded in the front-face mode. The incident angle was set at $20^{\circ}$ to avoid overlapping of the fluorescence peaks and reflection peak. To achieve sufficient intensity and resolution, the excitation and emission wavelength were carefully selected and set at 330 and $410 \mathrm{~nm}$, respectively. Excitation and emission bandpasses were set to 4 and $16 \mathrm{~nm}$ for excitation spectra, and 16 and $4 \mathrm{~nm}$ for emission spectra, respectively.

\section{Results and Discussion}

Influence of Initial Film Thickness on Grafted Amount. It is expected that the amount of telechelic grafted to the functionalized surface at long annealing times will be a function of the initial film thickness for thin films; thus, the relationship between the initial film thickness and the final grafted amount was examined. The initial film thickness is controlled by the concentration of the polymer solution from which the thin film is spin-coated as shown in Figure 1a. This plot shows that larger molecular weigh tend to generate thicker layers for identical conditions, especially at higher concentration. Three samples (D3.7K, D32K, and D125K) were grafted at $150{ }^{\circ} \mathrm{C}$ for 4 days and subsequently examined. A study of the kinetics of the grafting reaction showed that the amount of grafted material did not change significantly after 4 days at $150{ }^{\circ} \mathrm{C}$; thus, the 

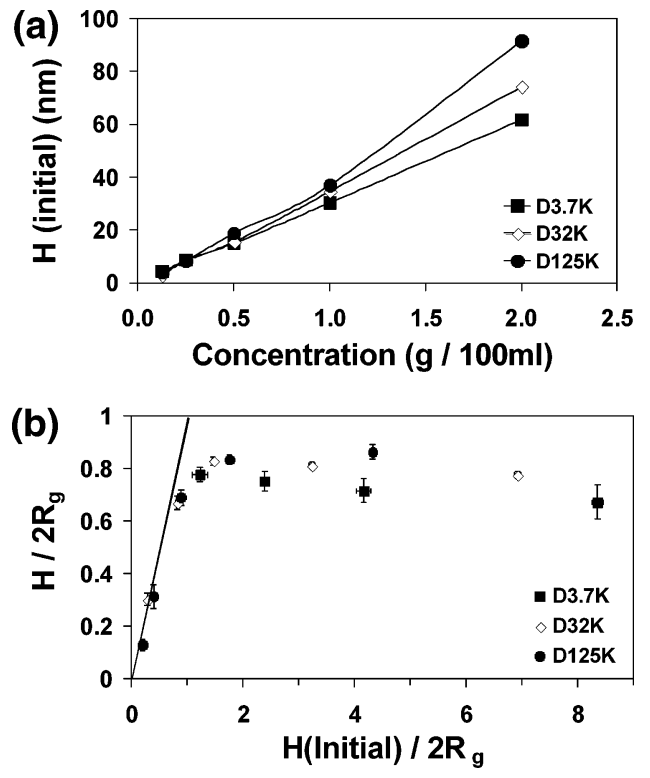

Figure 1. (a) Thickness of spin-coated films as a function of solution concentration for D3.7K, D32K, and D125K. (b) Reduced grafted layer thickness $H / 2 R_{\mathrm{g}}$ as a function of reduced initial film thickness.

extent of grafted material is taken as that which is measured after 4 days annealing.

Figure $1 \mathrm{~b}$ shows the thickness of the grafted layer as a function of the thickness of the spin-coated film. This figure shows that the grafted thickness increases with initial film thickness when its thickness is less than $2 R_{\mathrm{g}}$. The data in this regime fall reasonably well on a line where $H / 2 R_{\mathrm{g}}=H$ (initial)/ $2 R_{\mathrm{g}}$, suggesting that almost all of available telechelic polymers is grafted in this regime. The grafted layer thickness stops increasing with initial film thickness when the initial film thickness is above $2 R_{\mathrm{g}}$, implying that a saturation of the surface is attained.

The fact that most reactive polymers can be grafted onto the surface when the initial thickness is less than $2 R_{\mathrm{g}}$ provides a straightforward method to control the amount of grafted chains accurately. The grafted layer formed in this manner should be in the mushroom regime where the conformation of the grafted chains are not influenced by its neighbors and therefore are not stretched. Grafted loops in this mushroom regime are expected to exhibit favorable adhesion properties, as one would expect that these loops can efficiently entangle with matrix polymer chains. Therefore, it is anticipated that the adhesive properties of this modified substrate can be tailored by controlling the initial film thickness from which the grafted layer is formed.

Molecular Weight Effects. To investigate the importance of the telechelic chain length on the structure of the grafted layer, thin films of all telechelic dPS samples listed in Table 1 were annealed at $150{ }^{\circ} \mathrm{C}$ for 4 days on an epoxy functionalized surface. To minimize any systematic error that may result from the variation of surface functionality among different batches of $\mathrm{Si}$-epoxy surfaces, all samples discussed in this section were fabricated using the same epoxy functionalized substrate. The measured grafted layer thicknesses $(H)$ are plotted as a function of telechelic molecular weight in Figure 2a. This data shows that the grafted layer thickness increases with telechelic molecular weight. To further understand this chain length dependence, the surface density of each layer is calculated using eq 1:

$$
\sigma=\frac{H N_{\mathrm{av}} \rho_{\mathrm{dPS}}}{\mathrm{MW}}
$$
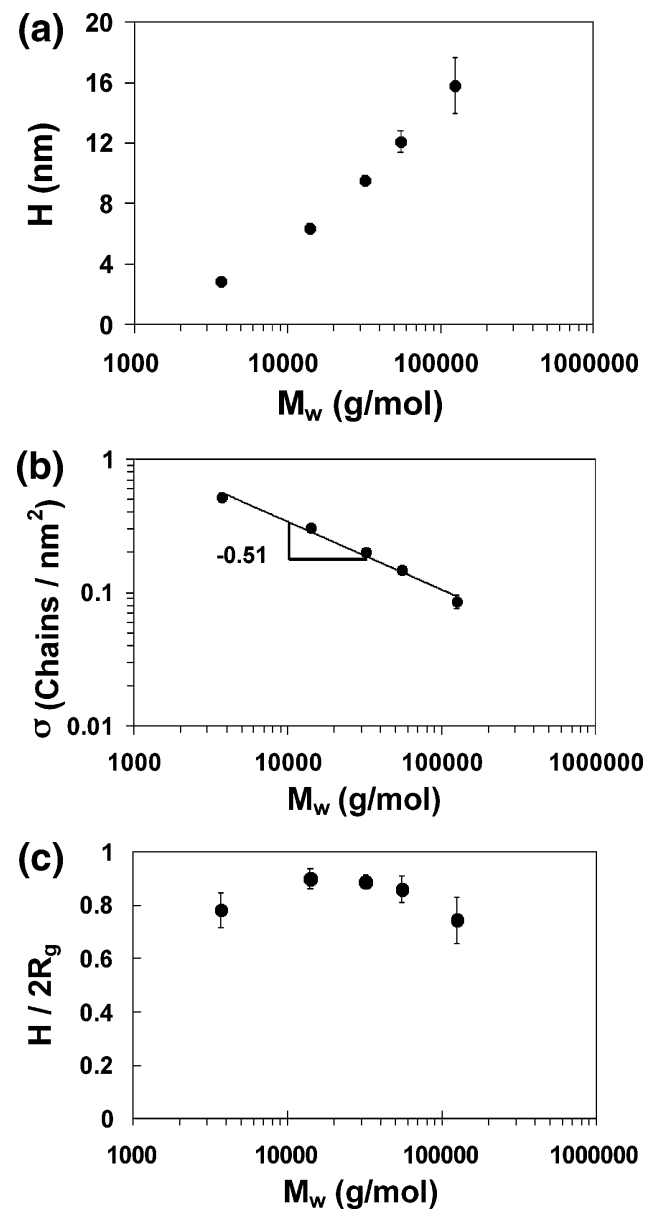

Figure 2. (a) Grafted layer thickness $(H)$ as a function of telechelic molecular weight $\left(M_{\mathrm{w}}\right)$. (b) Surface density $(\sigma)$ as a function of telechelic molecular weight $\left(M_{\mathrm{w}}\right)$. (c) Reduced grafted layer thickness $\left(H / 2 R_{\mathrm{g}}\right)$ as a function of telechelic molecular weight.

In eq $1, N_{\mathrm{av}}$ is Avogadro's number, $\rho_{\mathrm{dPS}}$ is the density for bulk dPS, and MW is the telechelic molecular weight. It should be noted that the surface density calculated here is the number of chains per unit area. As it is expected that the telechelics will form doubly bound chains (loops), the actual number of tethering sites per unit area should be larger than that estimated by eq 1 . To simplify the discussion yet retain the essential physics, the relationship between the surface density of chains and the molecular weight defined in eq 1 will be used as a measure of the surface density.

Figure $2 \mathrm{~b}$ shows the dependence of the surface density on telechelic molecular weight. As shown in Figures $2 \mathrm{~b}$ and $1 \mathrm{~b}$, the surface density scales as $\mathrm{MW}^{-0.5}$. This scaling behavior has been predicted by Luzinov et al. ${ }^{37}$ based on a steric argument; i.e., $H$ scales as $R_{\mathrm{g}}, \sigma \propto H / M_{\mathrm{w}}$ and $R_{\mathrm{g}} \propto M_{\mathrm{w}}{ }^{1 / 2}$. However, when they examined the grafting of monochelic PS $-\mathrm{COOH}$ onto an epoxysilane monolayer, this scaling law was not observed. In their study, a dramatic decrease of the grafted amount and surface density was observed when molecular weight exceeds ca. $40000 \mathrm{~g} / \mathrm{mol}$. This molecular weight is close to the critical entanglement molecular weight $M_{\mathrm{c}}=31200 \mathrm{~g} / \mathrm{mol}$ of PS. ${ }^{45}$ They interpreted this data to indicate that the low surface density for high molecular weight polymers is the result of a low effective reaction rate, which in turn, is due to the slow diffusion when the molecular weight is larger than $M_{\mathrm{c}}{ }^{46,47}$ In other words, the slow kinetics of the grafting reaction is responsible for the lower surface density. It should be noted that this argument is based on the assumption that the grafting process is diffusioncontrolled and the functional groups are sufficiently reactive. 
The grafting mechanism, i.e., whether it is diffusion or reaction controlled, is still an open question and a major objective of this manuscript is to address this question.

To compare the results from samples with different chain length, the film thickness of the grafted layers $(H)$ were normalized by $2 R_{\mathrm{g}}$, which is used as an approximate measure of the size of the free polymer chains in the melt. Radii of gyration $R_{\mathrm{g}}$ were estimated using $R_{\mathrm{g}}=A M_{\mathrm{w}}{ }^{1 / 2}$, where $A=0.3$ $\AA \mathrm{mol}^{1 / 2} \mathrm{~g}^{-1 / 2} \cdot{ }^{48}$

The normalized grafted layer thickness $\left(H / 2 R_{\mathrm{g}}\right)$ exhibits a very weak chain length dependence. As shown in Figure $2 c$, all values of $H / 2 R_{\mathrm{g}}$ range from 0.75 to 0.9 . It is expected that the thickness of a grafted film will approach $2 R_{\mathrm{g}}$, as has been observed by other researchers for singly bound chains. ${ }^{49,50}$ However, a tethered loop under similar conditions will differ in size and extension than that of a singly bound chain, as demonstrated theoretically and experimentally. For instance, Hesselink ${ }^{51}$ calculated the segment density distribution for both singly tethered chains (tail) and doubly tethered chains (loop) based on random walk statistics. According to this calculation, a grafted loop is about $\sqrt{3 / 7}$ less extended at the surface than a singly bound chain of the same length. In other experimental studies, it was found that the conformation of a doubly tethered chain is close to that of singly tethered with half the chain length. ${ }^{52-54}$ Therefore, the $R_{\mathrm{g}}$ of a doubly tethered chain should be roughly $\sqrt{1 / 2} \approx 0.7$ of that of a singly bound chain with the same chain length, consistent with Hesselink's theoretical result $(\sqrt{3 / 7} \approx 0.65)$. Thus, one would expect that the normalized thickness $H / 2 R_{\mathrm{g}}$ of a grafted loop will approach 0.7 . If we consider that the saturation value of $H / 2 R_{\mathrm{g}}$ is equal to 1 for the singly bound system, the fact that $H / 2 R_{\mathrm{g}}=0.75-0.9$ in our case indicates that a substantial amount of loops have been formed.

The observation that the grafted layer thickness is similar to the size of an unperturbed chain suggests that during the grafting process, further grafting is inhibited after most polymer chains in the first layer near the surface have been grafted. Once these polymer chains graft at the interface, the approach of additional functionalized polymers toward the interface is suppressed. It should be noted that the grafted amount obtained experimentally is a kinetically limited value. This means that any factors that affect the kinetics of the reaction, such as surface functionality and annealing temperature, will also impact the grafted layer characteristics.

An explanation for the observed differences between the grafting behavior of telechelics and monochelics for high molecular weight polymers remains elusive. We do not have a definite explanation for the observed differences, but we believe that an understanding of the loop conformation and formation process and its impact on the grafting process are important in developing this understanding.

Figure 3a details the role of telechelic molecular weight on the kinetics of the grafting process where $\sigma$ increases roughly with the logarithm of the grafting time. The slope of this curve $\mathrm{d} \sigma /(\mathrm{d} \log t)$, which is a measure of the grafting rate, increases with decreasing molecular weight. However, if the reduced grafted thickness, $H / 2 R_{\mathrm{g}}$, is plotted as a function of $\log t$, no significant molecular weight dependence is observed for these deuterated samples as shown in Figure 3b. These results provide very important information concerning the mechanism of grafting as will be discussed in a later section.

Influence of Annealing Temperature on Grafting Kinetics. The annealing temperature is expected to impact the grafting kinetics in two ways, by increasing both the mobility of the
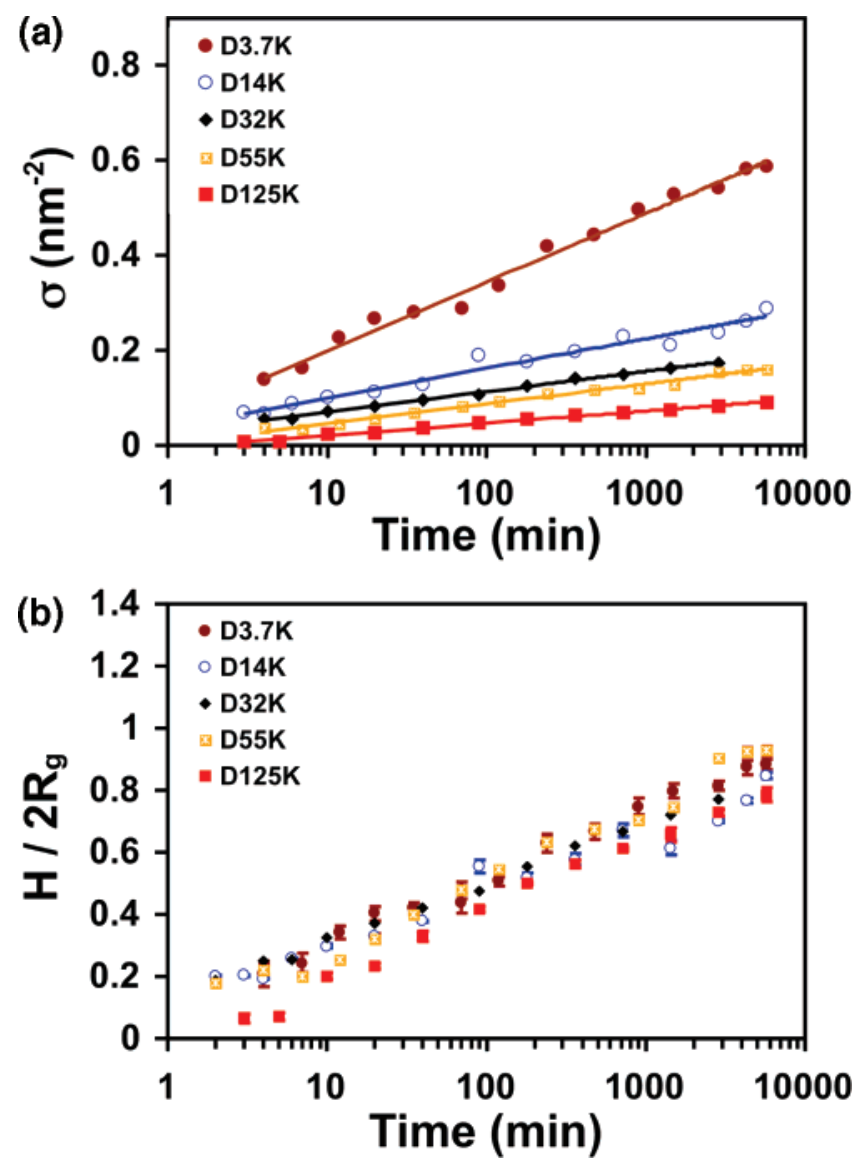

Figure 3. (a) Evolution of surface density $(\sigma)$ with annealing time. (b) Time dependence of reduced grafted layer thickness $\left(H / 2 R_{\mathrm{g}}\right)$ for all of samples.

telechelics and the rate of the reaction. Increasing temperature will speed up the diffusion of the telechelic and thus increase the rate of the grafting, if the process is diffusion-controlled. Therefore, examination of the temperature dependence of the grafting process provides important information that can be utilized to more fully understand the mechanism of the grafting process.

Figure 4a shows the temperature dependence of the graft layer thickness temporal change. As shown in Figure 4a, the grafting kinetics becomes faster with increasing annealing temperature from 150 to $180{ }^{\circ} \mathrm{C}$.

However, it remains unclear whether the enhanced grafting rate is the result of an increase in the diffusion rate of the telechelics to the surface or from the enhanced reactivity, or both. To address this question, the data can be analyzed assuming the increase in temperature alters only the reaction rate constant, and the activation energy of the reaction can be determined from this data. This is accomplished by making an Arrhenius plot of a second-order reaction as shown by Figure 4b. The annealing time to reach half the long-time $(\sim 4 \mathrm{~h})$ grafted amount, $t_{1 / 2}$, was found for three annealing temperatures $\left(150,165\right.$, and $\left.180^{\circ} \mathrm{C}\right)$, and the activation energy $\left(E_{\mathrm{a}}\right)$ of the reaction can be determined from this data using the Arrhenius equation:

$$
\frac{1}{t_{1 / 2}}=\exp \left(\frac{-E_{\mathrm{a}}}{R T}\right)
$$

Using this data, $E_{\mathrm{a}}$ is determined to be $89 \pm 16 \mathrm{~kJ} / \mathrm{mol}$. This value is very close to that reported for epoxy-carboxylic acid systems obtained by Hirose et al. ${ }^{55,56}$ and from the examination 

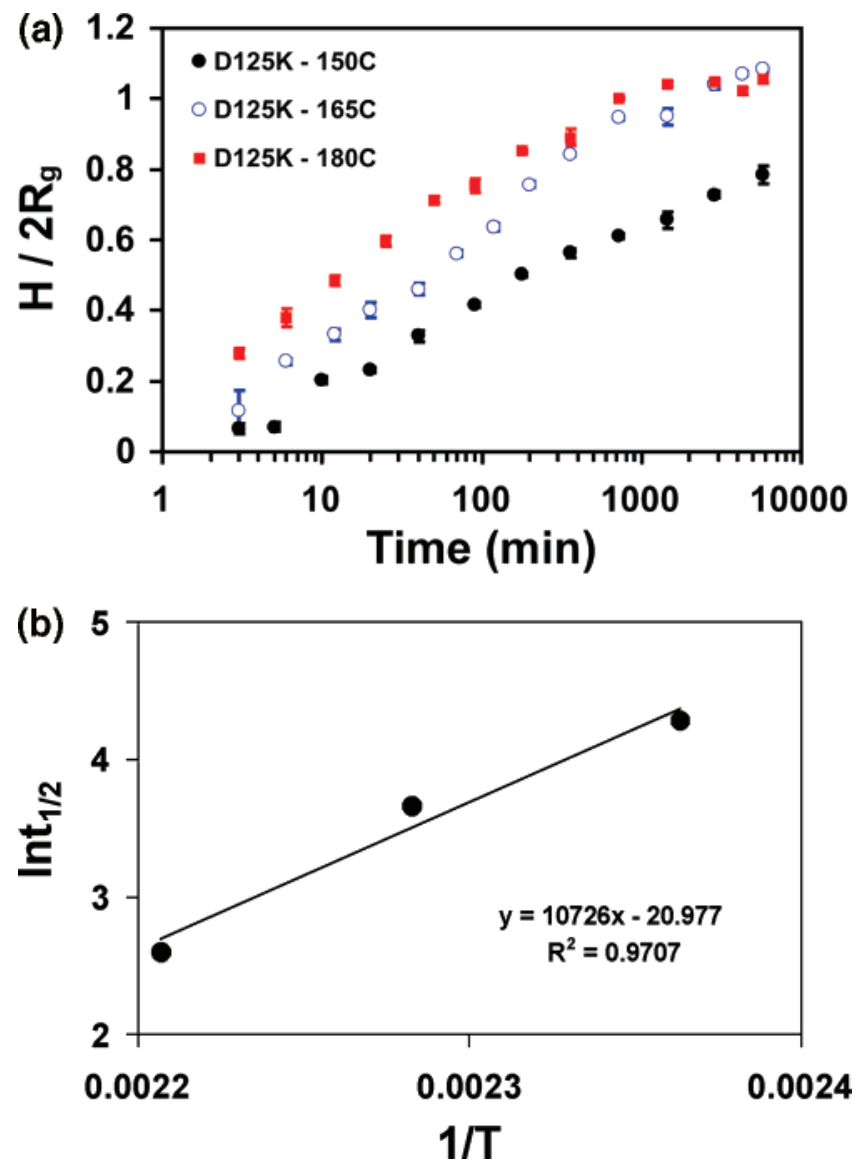

Figure 4. (a) Time dependence of the reduced grafted layer thickness $\left(H / 2 R_{\mathrm{g}}\right)$ at 150,165 , and $180{ }^{\circ} \mathrm{C}$ for D125K. (b) Arrhenius plot for grafting kinetics of $\mathrm{D} 125 \mathrm{~K}$ where $t_{1 / 2}$ is the annealing time required to reach half of the final grafted amount. The activation energy $\left(E_{\mathrm{a}}\right)$ calculated from the plot is $89 \pm 16 \mathrm{~kJ} / \mathrm{mol}$.

of the homogeneous coupling of PS- $\mathrm{COOH}$ and PS-epoxy by Guégan et al., where an $E_{\mathrm{a}}$ of $84 \mathrm{~kJ} / \mathrm{mol}$ was observed. ${ }^{57}$ This value is much higher than the activation energy for diffusion processes $(<30 \mathrm{~kJ} / \mathrm{mol})$; therefore, this result strongly suggests that the grafting process is predominantly reaction controlled, although the effect of diffusion on the grafting process cannot be excluded completely.

Influence of Surface Functionality on the Grafting Kinetics. The concentration of epoxy groups on the substrate will also impact the grafting kinetics in a predictable way if the grafting is reaction controlled. If this is true, the grafting rate should be proportional to the concentration of the epoxy groups since the reaction between the carboxylic acid group and epoxy group is a second-order reaction; i.e., the reaction rate is proportional to the product of the concentration of epoxy groups and the concentration of carboxylic acid groups. Thus, the grafting kinetics were studied for surfaces with varying concentration of epoxy groups. These surfaces were created by the formation of a mixed silane layer from a combination of two types of silanes, one with epoxy groups and the other with methyl end groups.

In this procedure, a $1 \%$ solution of the silane mixture with various proportions of the two silanes were made and used to create the silane monolayer as described in the experimental section. To characterize the monolayer of the silane mixture, the advancing contact angle of water and ellipsometric thickness were measured. As shown in Figure 5a, the contact angle varies from 57.5 to $53^{\circ}$ with increasing mole fraction of epoxysilane
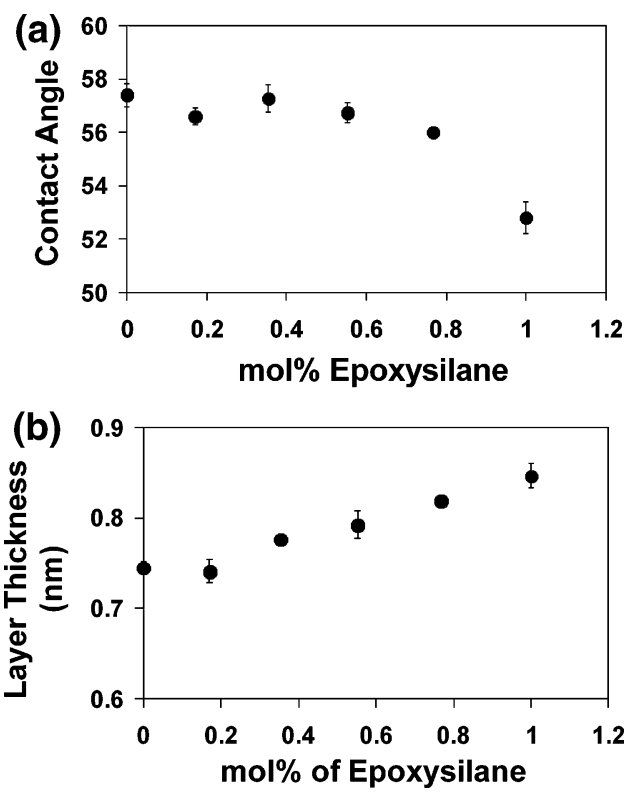

Figure 5. (a) Water advancing contact angle and (b) ellipsometric thickness of the mixed silane layer as a function of the molar fraction of epoxysilane in the silane mixture.

in the silane solution. In our studies, the contact angle for the pure MPS monolayer is much lower than what is expected for a surface covered with hydrophobic methyl groups. We speculate that the lower contact angle is caused by the proximity of the oxygen to the terminal $-\mathrm{CH}_{3}$ group. Because of tilt or local disorder, this oxygen may be exposed, thus reducing the measured contact angle of this surface. In the present case, the narrow range of the contact angles makes it difficult to accurately deduce the composition of the silane layer from the contact angle. However, if the adsorption of these two silanes on the silicon wafer occurs at a similar rate, the composition of the silane monolayer will be similar to that of the solution from which the monolayer was created. For the purpose of this discussion, we will make this assumption, but we emphasize that this correlation has not been verified.

The ellipsometric thicknesses of (3-glycidyloxypropyl)trimethoxysilane and 3-methoxypropyltrimethoxysilane monolayers have been determined to be ca. 0.85 and $0.75 \mathrm{~nm}$, respectively. The thickness for the mixed silane layer with varying composition is between these two values as shown in Figure $5 b$, confirming that the functional layer is a monolayer.

Figure 6 shows the time dependence of the surface density for the grafting process of the D125K telechelic on the silane monolayer with nominal molar fractions of epoxysilane of $25 \%$, $50 \%$, and $100 \%$. The surface density of the epoxy groups on the monolayer created from pure epoxysilane solutions has been estimated by Luzinov et al. ${ }^{36}$ to be ca. 6 epoxy groups $/ \mathrm{nm}^{2}$. Therefore, the nominal surface density for the surfaces with $25 \%$ and $50 \%$ epoxysilane are approximately 1.5 and 3 epoxy groups/ $\mathrm{nm}^{2}$, respectively. Figure 6 clearly shows that the kinetics of the grafting rate becomes faster with an increase in the epoxy surface density, indicating the critical role of surface functionality in the grafting kinetics. This result also supports the interpretation that the grafting process is reaction controlled, and this will be discussed in more detail in the next section.

Grafting Mechanism: Diffusion-Controlled or Reaction Controlled? The in depth studies that detail how molecular weight, annealing temperature, and surface functionality influence the grafting kinetics provide valuable information that can 


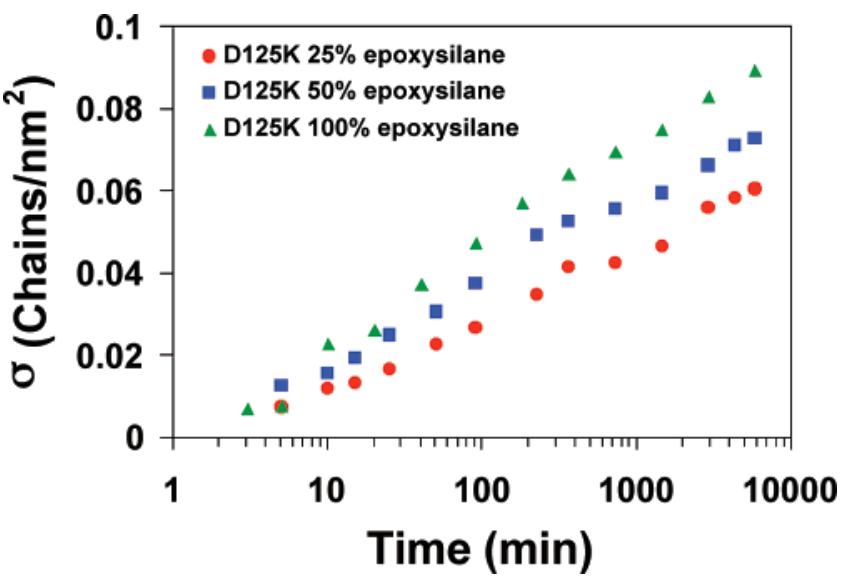

Figure 6. Time dependence of surface density for mixed silane layers with nominal epoxy surface density of $6 / \mathrm{nm}^{2}, 3 / \mathrm{nm}^{2}$, and $1.5 / \mathrm{nm}^{2}$.

be used to elucidate the dominant grafting mechanism. It appears that each of these results indicate that the grafting process is reaction controlled, although the impact of the diffusion rate of the telechelic cannot be completely rejected as an important factor in the grafting process.

Similar systems have also been studied by other researchers and comparison of our results to theirs may provide further insight into this problem. Using neutron reflectivity and helium(3) nuclear reaction analysis, Clarke et al. ${ }^{58}$ investigated the physical adsorption of end-functionalized dPS- $\mathrm{COOH}$ on a silicon wafer from a PS matrix. They found that in order to explain the kinetics data using a model based on a diffusioncontrolled mechanism, the diffusion coefficient must be reduced by 2 orders of magnitude from the expected values. This suggests that other factors beyond diffusion must exist that influence the grafting process. In another study, to determine whether the interfacial reaction of end-functionalized polymers at a soft interface is diffusion-controlled or reaction-controlled, Schulze et al. ${ }^{59}$ employed a trilayer film in which a PS layer was sandwiched by an amine functionalized dPS layer and an anhydride functionalized PMMA layer. Using forward recoil spectrometry (FRES), it was found that the time for the dPS$\mathrm{NH}_{2}$ chains to diffuse through the dPS layer is much shorter than the time when the reaction became noticeable. Therefore, the interfacial reaction is not solely determined by the diffusion of the functionalized polymer to the reactive interface. The reaction limited nature of similar interfacial reactions $27,28,31,57,60,61,65,66$ has also been observed.

To understand these results, Kramer ${ }^{61}$ proposed a model to predict the kinetics of the grafting process that is either diffusioncontrolled or reaction-controlled. For this model, in the case of a diffusion-controlled process, the grafting rate $\mathrm{d} \sigma / \mathrm{d} t$ is expressed as

$$
\frac{\mathrm{d} \sigma}{\mathrm{d} t}=D \frac{\mathrm{d} n}{\mathrm{~d} z}
$$

where $D$ is the self-diffusion coefficient of the reacting chain, $z$ is the distance from the surface, and $\mathrm{d} n / \mathrm{d} z$ is approximately equal to $n * / a$. In this relationship, $a$ is the statistical segment length and $n *$ is the number density (number per unit volume) of end functional groups within a thin layer at the interface, and it can be calculated as

$$
n^{*}=n_{\infty} \exp \left(-\frac{\mu^{*}}{k_{\mathrm{B}} T}\right)
$$

where $n_{\infty}=2 \rho_{0} / N$ is the number density of end-functional group in the bulk, $\rho_{0}$ is the segment density of the reactive polymers, and $N$ is the degree of polymerization. From this equation, the relationship between the interfacial excess, $z^{*}$, and time is derived as

$$
\int_{0}^{\frac{Z^{*}}{R_{\mathrm{g}}}} \exp \left[\frac{\mu^{*}\left(z^{*} / R_{\mathrm{g}}\right)}{k_{\mathrm{B}} \mathrm{T}}\right] \mathrm{d}\left(\frac{z^{*}}{R_{\mathrm{g}}}\right)=\frac{t}{\tau_{D}}
$$

where $\tau_{D}=a R_{\mathrm{g}} / D$ is the characteristic time of the process.

In the reaction-controlled process, the reaction at the interface is assumed to follow second-order kinetics and the reaction is irreversible. The rate of grafting can thus be calculated as

$$
\frac{\mathrm{d} \sigma}{\mathrm{d} t}=a \frac{\mathrm{d}[\mathrm{GPS}]}{\mathrm{d} t}=a k_{\mathrm{f}} n^{*}[\mathrm{ES}]
$$

where, for our system, [GPS] represents the concentration of grafted PS at the interface, $k_{\mathrm{f}}$ is the bimolecular forward rate constant, and [ES] represents the concentration of epoxysilane on the surface. Replacing $n *$ and integrating yields an equation with a similar form to eq 5 :

$$
\int_{0}^{\frac{Z^{*}}{R_{\mathrm{g}}}} \exp \left[\frac{\mu^{*}\left(z^{*} / R_{\mathrm{g}}\right)}{k_{\mathrm{B}} \mathrm{T}}\right] \mathrm{d}\left(\frac{z^{*}}{R_{\mathrm{g}}}\right)=\frac{t}{\tau_{\mathrm{R}}}
$$

The primary difference between eqs 7 and 5 is that in eq 7, the characteristic time $\tau_{\mathrm{R}}$ becomes: $\tau_{\mathrm{R}}=R_{\mathrm{g}} / a k_{\mathrm{f}}[\mathrm{ES}]$.

Both eq 5 and eq 7 can be solved numerically, where the diffusion coefficient is calculated as $D=D_{0} / n^{2}$. For our system, $D_{0} \approx 2.677 \times 10^{6} \mathrm{~nm}^{2} / \mathrm{s}$ for PS at $153{ }^{\circ} \mathrm{C}$ in the bulk, ${ }^{62}$ and a statistical segment length of $a=0.67 \mathrm{~nm}$ was adopted. To utilize this model to interpret our data, we chose three samples with molecular weights that exceed the critical molecular weight $M_{\mathrm{c}}$ of polystyrene. For a diffusion-controlled system, the time evolution of the normalized grafted layer thickness $\left(z^{*} / 2 R_{\mathrm{g}}\right)$ with annealing time can be calculated and is shown in Figure 7 a for samples D32K, D55K, and D125K. The model predicts much faster kinetics than the experimental data by $1-4$ orders of magnitude. In addition, the model curves exhibit a strong molecular weight dependence, in contrast to the weak molecular weight dependence of the experimental kinetics data. These results clearly demonstrate that the grafting process in our system is not limited by the diffusion of the telechelic to the reactive surface through the bulk polymer.

A similar calculation for the reaction-controlled model was also completed using eq 7, where the surface concentration of epoxy groups $[\mathrm{ES}]=6 / \mathrm{nm}^{2}$ was used in this calculation. Figure $7 \mathrm{~b}$ displays the results of this calcualtion and the experimental data for D125K. In this plot, the initial stage $(\sim 100 \mathrm{~min})$ correlates well to the model, but significant deviation is observed in the late stage. It appears that this model overestimates the grafted amount at long times. Such an overestimate at long times by this model has also been observed in interfacial reactions at polymer/polymer interfaces ${ }^{63}$ Evidently, this model does not consider all parameters that impact the grafting process at longer times, including the difficulty of the reactive chain to diffuse through the layer of previously grafted chains.

Additionally, in Kramer's model, it is assumed that the diffusion of the reactive polymer in the grafted layer is identical to that in the bulk state. However, the diffusion in the grafted region may exhibit different behavior than that in the bulk state due to the reduced mobility of the grafted chains. For example, it has been reported by Tate et al. ${ }^{50}$ that the $T_{\mathrm{g}}$ of a grafted polystyrene film is substantially higher than that of an ungrafted 

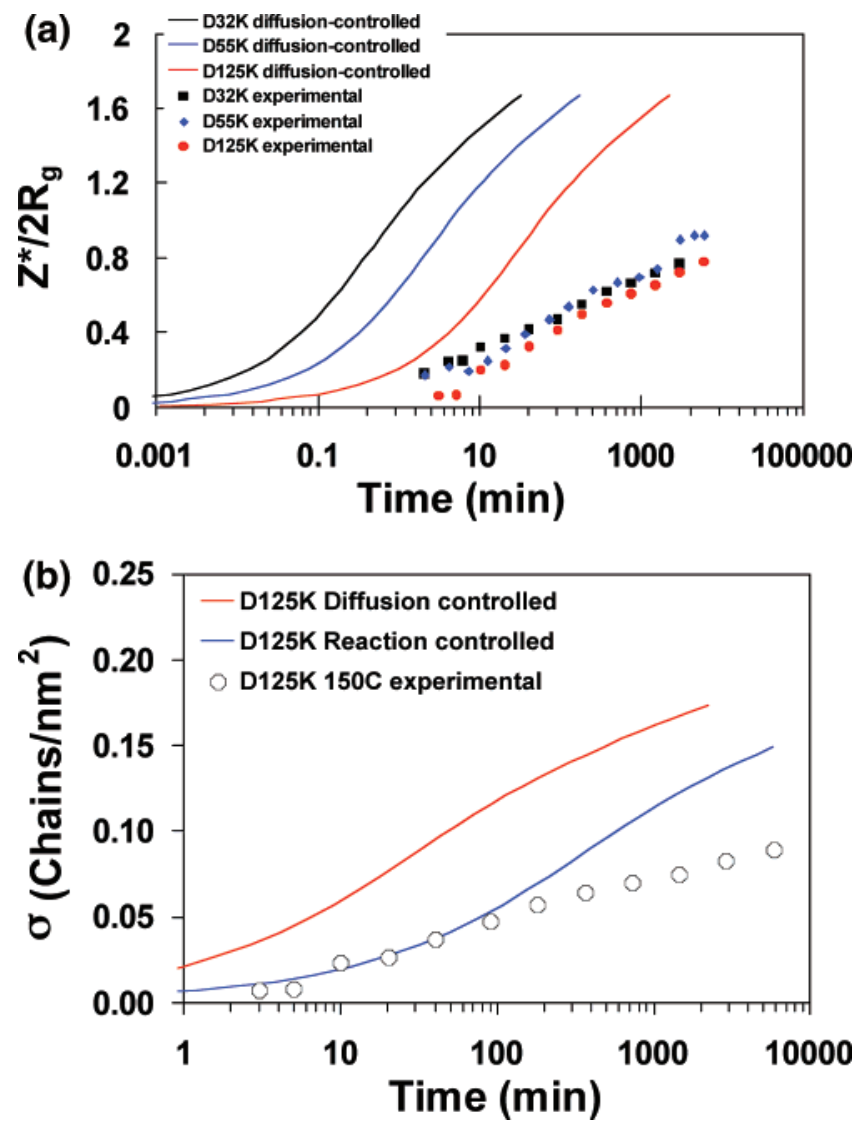

Figure 7. (a) Comparison of the kinetics curves (solid curves) calculated by Kramer's model assuming a diffusion-controlled mechanism with experimental data for D32K (black), D55K (blue), and D125K (red). (b) Fitting of a reaction-controlled mechanism model to the experimental data for $\mathrm{D} 125 \mathrm{~K}$ annealed at $150{ }^{\circ} \mathrm{C}$. As a comparison, the theoretical prediction for a diffusion-controlled process is also shown in the plot.

film. For a polymer thin film composed of both grafted PS (with an interfacial excess $\sim 2 R_{\mathrm{g}}$ ) and ungrafted PS, having molecular weight of $100 \mathrm{~kg} / \mathrm{mol}$, a $T_{\mathrm{g}}$ elevation of $25^{\circ} \mathrm{C}$ was observed. ${ }^{50}$ Their sample is very similar to ours in terms of the molecular weight, film thickness and final interfacial excess. In their study, the $T_{\mathrm{g}}$ was measured by local thermal analysis, which represents the average mobility of the chain in the thin film including both grafted chains and free chains. If we assume that the $T_{\mathrm{g}}$ elevation of $25^{\circ} \mathrm{C}$ can be applied to the free chains in the grafted region, the change in the diffusion coefficient due to this $T_{\mathrm{g}}$ variation can be estimated using the Williams-Landel-Ferry (WLF) equation as shown below: ${ }^{64}$

$$
-\log a_{\mathrm{T}}=\log \left[D(T) / D\left(T_{\mathrm{s}}\right)\right]=\frac{-C_{1}\left(T-T_{\mathrm{s}}\right)}{C_{2}+T-T_{\mathrm{s}}}
$$

Here $a_{\mathrm{T}}$ is a shift factor, $D(T)$ and $D\left(T_{\mathrm{S}}\right)$ are the diffusion coefficients at temperature $T$ and reference temperature $T_{\mathrm{s}}$, respectively. Universal values $C_{1}=17.44$ and $C_{2}=51.6 \mathrm{~K}$ are used, as the reference temperature $T_{\mathrm{s}}$ is chosen as $T_{\mathrm{g}} .{ }^{64}$ The $a_{\mathrm{T}}$ values at $150{ }^{\circ} \mathrm{C}$ are thus calculated for two different $T_{\mathrm{g}}$ values, 100 and $125^{\circ} \mathrm{C}$. The calculation shows that the $a_{\mathrm{T}}$ corresponding to $T_{\mathrm{g}}=100{ }^{\circ} \mathrm{C}$ is ca. $2.6 \times 10^{9}$ in contrast to $a_{\mathrm{T}}=2.03 \times 10^{6}$ for $T_{\mathrm{g}}=125^{\circ} \mathrm{C}$. If we assume $D\left(T_{\mathrm{g}}\right)$ is constant in both cases, the diffusion coefficient at $150{ }^{\circ} \mathrm{C}$ for the case of $T_{\mathrm{g}}=125^{\circ} \mathrm{C}$ is 3 orders of magnitude lower than that for the system with $T_{\mathrm{g}}$ $=100{ }^{\circ} \mathrm{C}$. In the early stage of the grafting process, there are vary few grafted chains, and this effect is negligible. However, this effect may become very important in the late stage of the grafting process, where there are more grafted chains. In this case, the diffusion of the polymer to the surface may become important in the late stages of the reaction, especially for high molecular weight chains. This might also contribute to the overestimation of the grafted amount in the late stage using Kramer's model, which does not include this effect.

Although a quantitative agreement between this model and our data is limited to early times, this correlation can be utilized to estimate $k_{\mathrm{f}}$ for our systems. The bimolecular rate constant $k_{\mathrm{f}}$ obtained by fitting the experimental data ranges from $3 \times 10^{-3}$ $\mathrm{nm}^{3} \mathrm{~s}^{-1}$ molecule ${ }^{-1}\left(\approx 1.7 \times 10^{-3} \mathrm{~kg} \mathrm{~s}^{-1} \mathrm{~mol}^{-1}\right)$ to $8 \times 10^{-3}$ $\mathrm{nm}^{3} \mathrm{~s}^{-1}$ molecule ${ }^{-1}\left(\approx 4.6 \times 10^{-3} \mathrm{~kg} \mathrm{~s}^{-1} \mathrm{~mol}^{-1}\right)$ for all the samples investigated at $150{ }^{\circ} \mathrm{C}$. These $k_{\mathrm{f}}$ values are the same order of magnitude, but significantly slower than those reported by Guégan et al. ${ }^{57}$ for the homogeneous coupling between PS$\mathrm{COOH}$ and PS-epoxy $\left(9.9 \times 10^{-3} \mathrm{~kg} \mathrm{~s}^{-1} \mathrm{~mol}^{-1}\right)$. The difference in these reaction rate constants may lie in the differences of the two systems. In Guégan's work, both reactive groups are mobile and thus can more readily undergo collisions that result in reaction than in our system, where the epoxy group is bound to the surface, and thus must rely on the mobility of the $-\mathrm{COOH}$ group on the telechelic PS to realize a collision between the two moieties that results in a successful coupling reaction.

This model can also be used to estimate the impact of certain parameters, such as $k_{\mathrm{f}}, N$, and [ES], on the grafting process and these predictions can be tested experimentally to provide further insight into the grafting process and methods to modify and control it.

First, the impact of the functionality of the surface on the grafting kinetics can be analyzed. In this analysis, eq 6 can be used to fit the data in Figure 6, where the previously determined $k_{\mathrm{f}}$ value of $\mathrm{D} 125 \mathrm{~K}$ at $150{ }^{\circ} \mathrm{C}$ is utilized and the concentration of the epoxy on the surface is allowed to vary. As shown in Figure 8a, the concentration of epoxy on the surface can be estimated for all surfaces from fits to Kramer's model at early times $(<100 \mathrm{~min})$. The concentration of epoxy on the surface determined from this calculation are 1.7 and $3.6 / \mathrm{nm}^{2}$, respectively, for the surfaces created from the $25 \%$ and $50 \%$ epoxysilane solutions, which approach those predicted by assuming that the composition of the surface is equal to that of the solution from which the monolayer is formed $\left(1.5 / \mathrm{nm}^{2}\right.$ and $3 / \mathrm{nm}^{2}$ ). This analysis, thus, indicates that the slowing down of the grafting kinetics that is observed when the surface functionality is reduced can be quantitatively described by assuming the grafting process is reaction-controlled.

Second, the influence of temperature on the kinetics can be similarly analyzed. The values of the bimolecular forward rate constant $k_{\mathrm{f}}$ for $\mathrm{D} 125 \mathrm{~K}$ grafted at 150,165 , and $180{ }^{\circ} \mathrm{C}$ can be obtained by fitting the experimental curves in Figure $4 \mathrm{a}$ to eq 7 , as shown in Figure $8 \mathrm{~b}$. The activation energy that is determined from the temperature dependence of these $k_{\mathrm{f}}$ values is ca. $99 \mathrm{~kJ} / \mathrm{mol}$, which is similar to what is obtained by using the $t_{1 / 2}$ values and literature data.

The above analyses, thus, strongly supports the conclusion that the grafting is reaction controlled, as has been observed for many reactions of polymers at itnerfaces. However, there have been reports of diffusion-limited reactions of polymer chains at a reactive interface and a deeper look into these competing processes may provide insight into this apparent contradiction. It should be noted that the difference in the time scale of the reaction-controlled process and that of the diffusioncontrolled process for the D125K sample is only about an order 

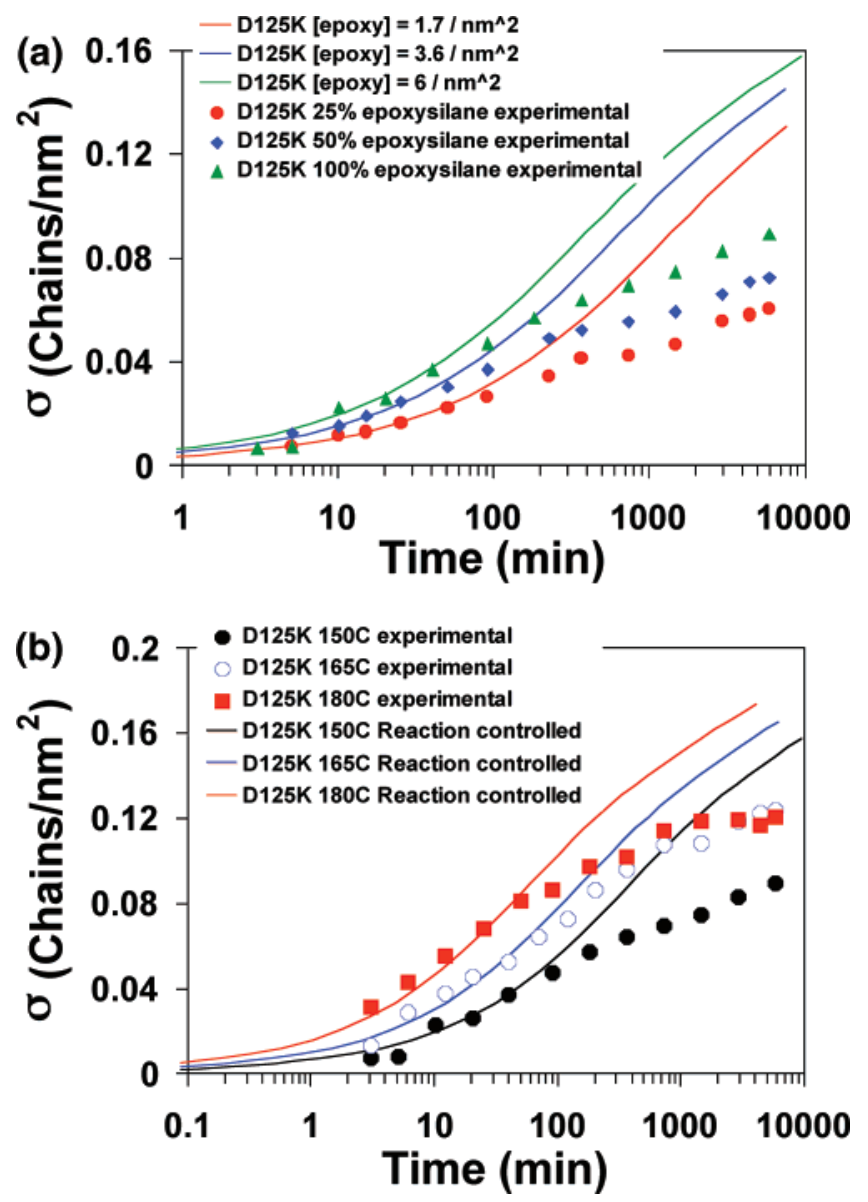

Figure 8. (a) Fitting of the kinetics curves to Kramer's model assuming reaction-controlled mechanism. Note that the same rate constant $k_{\mathrm{f}}$ is used in all fits. (b) Fitting of the kinetics curves to Kramer's model assuming a reaction-controlled for varying grafting temperatures.

of magnitude. This difference will be diminished as the molecular weight of the reactive chain increases or by decreasing the reaction temperature. Both modifications would increase the characteristic time $\tau_{\mathrm{D}}$ for diffusion, therefore making the effect of diffusion more important in the grafting process. The point where the diffusion process becomes the limiting process is when its characteristic time is larger than that of the reaction, i.e., $\tau_{\mathrm{D}}>\tau_{\mathrm{R}}$. Another way to think of this is that there is a crossover from reaction limited to diffusion limited behavior when $\tau_{\mathrm{D}}=\tau_{\mathrm{R}}$. In the present case, at an annealing temperature of $150{ }^{\circ} \mathrm{C}$, the critical molecular weight above which $\tau_{\mathrm{D}}$ exceeds $\tau_{\mathrm{R}}$ can be estimated as shown by Figure 9, which occurs at 1500 $\mathrm{kg} / \mathrm{mol}$. Above this critical molecular weight, the diffusioncontrolled mechanism should become dominant. As mentioned above, most studies on the interfacial reaction at a polymer/ substrate or polymer/polymer interface were found to be reaction-controlled. ${ }^{27,28,31,57,59,61,65,66}$ However, diffusion-controlled processes have been observed. For example, Harton et al. ${ }^{67}$ studied an interfacial reaction for a highly reactive complementary polymer pair at a low annealing temperature. A depletion layer of the reactive polymer near the grafting interface was observed using dynamic secondary ion mass spectrometry (DSIMS), which is consistent with a typical Fickian diffusion profile. ${ }^{68}$ In another work, they examined an interfacial reaction in supercritical $\mathrm{CO}_{2}$ at temperatures far below $T_{\mathrm{g}}{ }^{69}$ In a narrow annealing temperature range, both reactioncontrolled and diffusion-controlled behaviors were observed. Thus, these works indicate that it is possible to reach the diffusion-controlled regime through reducing the diffusion rate

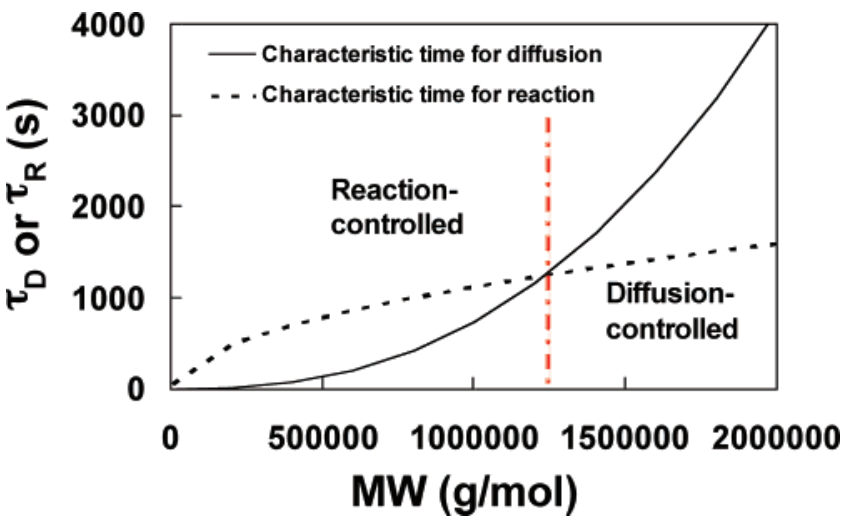

Figure 9. Characteristic times $\tau_{\mathrm{D}}$ and $\tau_{\mathrm{R}}$ in Kramer's model as a function of molecular weight. The crossing of these two curves denotes a critical molecular weight above which the grafting will become diffusion-controlled.

or enhancing the reactivity, and the analysis provided in Figure 9 provides insight into where these regions lie.

Thus, it is clear that the impact of the reactive chain diffusion may become important in the grafting of polymer chains to a reactive surface, and care should be taken into account in estimating its contribution to the process and assuming that the behavior of the reactive polymer near a surface is similar to its behavior in the bulk. This discrepancy may be a source of the lack of correlation between theory and experiment in a wide range of polymeric grafting processes, and further experiments in our group are underway to more thoroughly study this.

Temporal Evolution of Singly Bound Chains. Telechelic polymers functionalized at both ends can form doubly bound loops or singly bound tails at the surface. However, it remains unclear how the amount of loops varies with grafting time. Understanding the kinetics of the loop formation provides a method to tailor the surface properties, as the tethered chains with loop and tail configuration exhibit different surface behaviors.

In the present study, to monitor the kinetics of loop formation, the time dependence of the amount of singly bound chains during the grafting process is determined by labeling the free carboxylic end group of singly bound chains with a fluorescent probe, PDAM. The average distance between two neighboring fluorophores should be larger enough to avoid self-quenching. Therefore, the fluorescence intensity is taken to be proportional to the amount of the fluorescence probes attached to the singly bound chains grafted to the surface.

Figure 10 gives the evolution of the fluorescence intensity with the grafting time for samples with various molecular weights. The samples were grafted at $150{ }^{\circ} \mathrm{C}$ from films with initial thickness ca. $40 \mathrm{~nm}$. It can be clearly seen that for the sample with the lowest molecular weight $3.5 \mathrm{~kg} / \mathrm{mol}$, the amount of singly bound chains increases in the beginning, then reaches a plateau, followed by a decay at long times. This behavior qualitatively follows that which is observed by Smith in their simulation work, ${ }^{19}$ where, in the initial stage, most newly bound chains are singly attached. During this period, most reactions at the surface attach a new chain at one end, increasing the amount of singly bound chains. Competitively, free $-\mathrm{COOH}$ groups of the singly bound chains react with the epoxy group on the substrate, forming loops, which decreases the amount of singly bound chains. At a certain time, a balance between these competing reactions is achieved leading to a plateau in the number of singly bound chains. At longer times, the growth of the newly bound chains is inhibited by the existence of grafted 


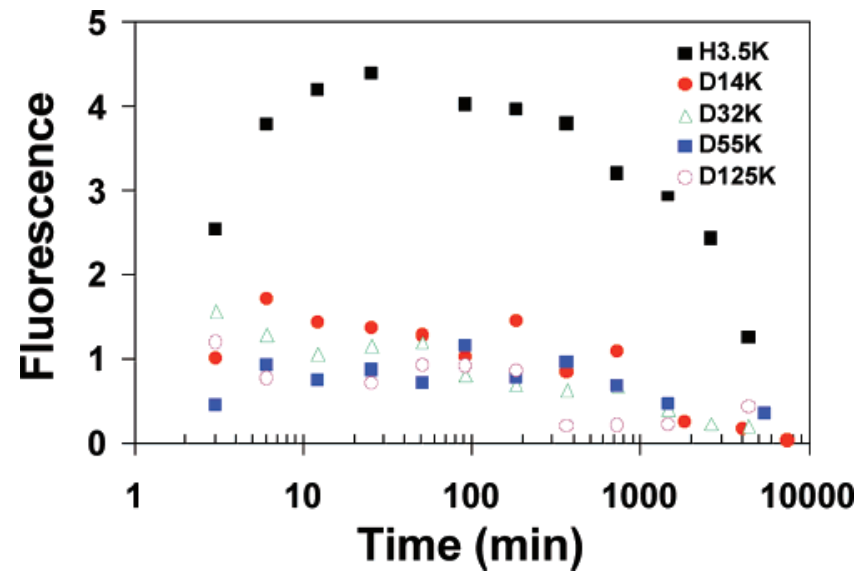

Figure 10. Fluorescence intensity, which is proportional to the amount of singly bound chains in the grafted layer, as a function of grafting time for samples with varying molecular weight.

chain layer, however, the free $-\mathrm{COOH}$ groups on the singly bound chains can still reach the surface to form loops. As a consequence, a decay of the amount of singly bound chain occurs at long times.

For the higher molecular weight samples, the trend is not as clear due to the presence of fewer chain ends. However, a plateau region followed by a decay of fluorescence intensity at long times can be observed in these samples. In each of these samples, the amount of fluorescence at long grafting times decays to a very small amount, further indicating that the primary product of the grafting of doubly end-functionalized telechelic chains to a functionalized surface are doubly bound chains.

\section{Conclusions}

The grafting process of telechelic polymers to a hard, functionalized surface has been extensively studied. The results clearly show that the surface density of chains can be readily directed by controlling the thickness of the initial film or the amount of functionality on the surface. The analysis of the impact of telechelic molecular weight, grafting temperature, and surface functionality clearly indicate that the grafting process is reaction controlled and that the predominant product of this grafting reaction is doubly bound chains. Moreover, these data provide an activation energy of the reaction process $(\sim 90 \mathrm{~kJ} /$ mol) and indicates that the diffusion of the reactive polymer to the functionalized surface can dominate the grafting process when grafting very long telechelic chains or at low temperatures.

Acknowledgment. This work was financially supported by the National Science Foundation through its Collaborative Research in Chemistry Program (CRC-CHEM 0304807).

\section{References and Notes}

(1) Smith, J. W.; Kramer, E. J.; Xiao, F.; Hui, J.; Reichharts, W.; Brown, H. J. Mater. Sci. 1993, 28, 4234.

(2) Smith, J. W.; Kramer, E. J.; Mills, P. J. J. Polym. Sci., Polym. Phys. 1994, 32, 1731.

(3) Derulle, M.; Tirrell, M.; Marciano, Y.; Hervet, H.; Léger, L. Faraday Discuss. 1994, 98, 55

(4) Norton, L. J.; Smiglova, V.; Pralle, M. U.; Hubenko, A.; Dai, K. H.; Kramer, E. J.; Hahn, S.; Begrlund, C.; DeKoven, B. Macromolecules 1995, 28, 1999.

(5) Klein, J.; Kumacheva, E.; Mahalu, D.; Perahia, D.; Fetters, L. J. Nature 1994, 370, 634.

(6) Klein, J. J. Аnnu. Rev. Mater. Sci. 1996, 26, 581.

(7) Brown, H. R. Faraday Discuss. 1994, 98, 47.

(8) Tomita, N.; Tamai, S.; Okajima, E.; Hirao, Y.; Ikeuch, K.; Ikada, Y. J. Appl. Biomater. 1994, 5, 175.
(9) Kilbey, S. M.; Watanabe, H.; Tirrell, M. Macromolecules 2001, 34, 5249.

(10) Shull, K. R. Faraday Discuss. 1994, 98, 203

(11) Yerushalmi-Rozen, R.; Klein, J.; Fetters, L. J. Science 1994, 263, 793.

(12) Luzinov, I.; Minko, S.; Senkovsky, V.; Voronov, A.; Hild, S.; Marti, O.; Wilke, W. Macromolecules 1998, 31, 3945.

(13) Reiter, G.; Auroy, P.; Auvray, L. Macromolecules 1996, 29, 2150.

(14) Ge, S. R.; Guo, L. T.; Rafailovich, M. H.; Sokolov, J. Langmuir 2001, $17,1687$.

(15) Reiter, G.; Khanna, R. Phys. Rev. Lett. 2000, 85, 2753.

(16) Reiter, G.; Khanna, R. Langmuir 2000, 16, 6351.

(17) Kerle, T.; Yerushalmi-Rozen, R.; Klein, J. Macromolecules 1998, 31 422.

(18) Müller, M.; MacDowell, L. G. Europhys. Lett. 2001, 55 (2), 221.

(19) Smith, G. D.; Zhang, Y.; Yin, F.; Bedrov, D.; Dadmun, M. D.; Huang, Z. Y. Langmuir 2006, 22, 664 .

(20) Dadmun, M. D. Macromolecules, 1996, 29, 3868

(21) Dadmun, M. D. Computational Studies, Nanotechnology, and Solution Thermodynamics of Polymer Systems; Kluwer Academic: New York, 2000; p 69.

(22) Eastwood, E.; Dadmun, M. D. Macromolecules 2002, 35, 5069.

(23) Eastwood, E.; Dadmun, M. D. Polymer 2002, 43, 6707.

(24) O'Brien, C.; Rice, J. K.; Dadmun, M. D. Eur. Polym. J. 2004, 40, 115.

(25) (a) Irvine, D. J.; Mayes, A. M.; Griffith-Cima, L. Macromolecules 1996, 29, 6037. (b) Irvine, D. J.; Mayes, A. M.; Satija, S. K.; Barker, J. G.; Sofia-Allgor, S. J.; Griffith, L. G. J. Biomed. Mater. Res. 1994, $28,329$.

(26) Hayashi, M.; Grüll, H.; Esker, A. R.; Weber, M.; Sung, L.; Satija, S K.; Han, C. C.; Hashimoto, T. Macromolecules 2000, 33, 6485.

(27) Jones, T. D.; Schulze, J. S.; Macosko, C. W.; Lodge, T. P. Macromolecules 2003, 36, 7212 .

(28) Yin, Z.; Koulic, C.; Pagnoulle, C.; Jérôme, R. Langmuir 2003, 19 , 453.

(29) Yu, X. B.; Wu, Y.; Li, B. Y.; Han, Y. C. Polymer 2005, 46, 3337.

(30) Jiao, J. B.; Kramer, E. J.; de Vos, S.; Möller, M.; Koning, C. Polymer 1999, 40, 3585 .

(31) Jiao, J. B.; Kramer, E. J.; de Vos, S.; Möller, M.; Koning, C. Macromolecules 1999, 32, 6261.

(32) Lyu, S. P.; Cernohous, J. J.; Bates, F. S.; Macosko, C. W. Macromolecules 1999, 32, 106.

(33) Kim, B. J.; Kang, H.; Char, K.; Katsov, K.; Fredrickson, G. H.; Kramer, E. J. Macromolecules 2005, 38, 6106.

(34) Ji, H. N.; Nonidez, W. K.; Advincula, R. C.; Smith, G. D.; Kilbey, S. M., II; Dadmun, M. D.; Mays, J. W. Macromolecules 2005, 38, 9950.

(35) Tsukruk, V. V.; Luzinov, I.; Julthongpiput, D. Langmuir 1999, 15 3029.

(36) Luzinov, I.; Julthongpiput, D.; Liebmann-Vinson, A.; Creeger, T. Foster, M. D.; Tsukruk, V. V. Langmuir 2000, 16, 504.

(37) Luzinov, I.; Julthongpiput, D.; Malz, H.; Pionteck, J.; Tsukruk, V. V. Macromolecules 2000, 33, 1043.

(38) Luzinov, I.; Julthongpiput, D.; Tsukruk, V. V. Macromolecules 2000 $33,7629$.

(39) Heuberger, M.; Zach, M.; Spencer, N. D. Science 2001, 292, 905.

(40) Marx, E.; Walzer, K.; Less, R. J.; Raithby, P. R.; Stokbro, K.; Greenham, N. C. J. Org. Electron. 2004, 5, 319.

(41) Huang, H. Q.; Penn, L. S. Macromolecules 2005, 38, 4837.

(42) Nimura, N.; Kinoshita, T.; Yoshida, T.; Uetake, A.; Nakai, C. Anal. Chem. 1988, 60, 2067.

(43) Yan, B.; Liu, L.; Astor, C. A.; Tang, Q. Anal. Chem. 1999, 71, 4564

(44) (a) Iwamura, M.; Ishikawa, T.; Koyama, Y.; Sakuma, K.; Iwamura H. Tetrahedron Lett. 1987, 28, 679. (b) Yoshida, T.; Uetake, A.; Nakai, C.; Nimura, N.; Kinoshita, T. J. Chromatogr. 1988, 456, 421. (c) Iohan, F.; Monder, C.; Cohen, S. J. Chromatogr. 1991, 564, 27. (d) Scneede, J.; Ueland, P. M. Anal. Chem. 1992, 64, 315.

(45) Wool, R. P. Polymer Interfaces: Structure and Strength: Hanser/ Gardner Pub.: Cincinnati, OH, 1995.

(46) O'Shaghnessy, B.; Sawhney, U. Phys. Rev. Lett. 1996, 76, 3444.

(47) O'Shaghnessy, B.; Sawhney, U. Macromolecules 1996, 29, 7230.

(48) Brandrup, J.; Immergut, E. H. editors. Polymer Handbook, 3rd ed.; Wiley: New York, 1989; VII 38, V 82.

(49) Mansky, P.; Liu, Y.; Huang, E.; Russell, T. P.; Hawker, C. Science 1997, 275, 1458.

(50) Tate, R. S.; Fryer, D. S.; Pasqualini, S.; Montague, M. F.; de Pablo, J. J.; Nealey, P. F. J. Chem. Phys. 2001, 115, 9982.

(51) Hesselink, Th. F. J. Phys. Chem. 1967, 71, 1861.

(52) Patel, S.; Tirrell, M.; Hadziioannou, G. Colloids Surf. 1988, 31, 157.

(53) Anastassopoulos, D. L.; Vradis, A. A.; Toprakcioglu, C.; Smith, G S.; Dai, L. Macromolecules 1998, 31, 9369.

(54) Alonzo, J.; Huang, Z. Y.; Liu, M.; Mays, J. W.; Toomey, R.G.; Dadmun, M. D.; Kilbey, S. M., II. Macromolecules 2006, 39, $8434-$ 8439. 
(55) Hirose, S.; Hatakeyama, T.; Hatakeyama, H. Macromol. Symp. 2003, 197, 157.

(56) Hirose, S.; Hatakeyama, T.; Hatakeyama, H. Macromol. Symp. 2005, $224,343$.

(57) Guégan, P.; Macosko, C. W.; Ishizone, T.; Hirao, A.; Nakahama, S. Macromolecules 1994, 27, 4993.

(58) Clarke, C. J.; Jones, R. A. L.; Edwards, J. L.; Clough, A. S.; Penfold, J. Polymer 1994, 35, 4065.

(59) Schulze, J. S.; Cernohous, J. J.; Hirao, A.; Lodge, T. P.; Macosko, C W. Macromolecules 2000, 33, 1191.

(60) Schulze, J. S.; Moon, B.; Lodge, T. P.; Macosko, C. W. Macromolecules 2001, 34, 200.

(61) Kramer, E. J. Isr. J. Chem. 1995, 35, 49.

(62) Zheng, X.; Sauer, B. B.; van Alsten, J. G.; Schwarz, S. A.; Rafailovich, M. H.; Sokolov, J.; Rubinstein, M. Phys. Rev. Lett. 1995, 74, 407.
(63) Coote, M. L.; Gordon, D. H.; Hutching, L. R.; Richards, R. W.; Dalgliesh, R. M. Polymer 2003, 44, 7689.

(64) Williams, M. L.; Landel, R. F.; Ferry, J. D. J. Am. Chem. Soc. 1955 77,3701 .

(65) Oyama, H. T.; Inoue, T. Macromolecules 2001, 34, 3331.

(66) Kim, H. J.; Lee, K. J.; Seo, Y. Macromolecules 2002, 35, 1267.

(67) Harton, S. E.; Stevie, F. A.; Ade, H. Macromolecules 2005, 38, 3543.

(68) Crank, J. The Mathematics of Diffusion, 2nd ed.; Oxford University Press: New York, 1975.

(69) Harton, S. E.; Stevie, F. A.; Spontak, R. J.; Koga, T.; Rafailovich, M. H.; Sokolov, J. C.; Ade, H. Polymer 2005, 46, 10173.

MA071836Q 